\title{
Development of Lecithin Nanoemulsion Based Organogels for Permeation Enhancement of Metoprolol through Rat Skin
}

\author{
J. Varshosaz, ${ }^{1,2}$ S. Andalib, ${ }^{1}$ M. Tabbakhian, ${ }^{1}$ and N. Ebrahimzadeh ${ }^{1}$ \\ ${ }^{1}$ Department of Pharmaceutics and Novel Drug Delivery Systems Research Centre, School of Pharmacy and Pharmaceutical Sciences, \\ Isfahan University of Medical Sciences, Isfahan 81746-73461, Iran \\ ${ }^{2}$ Department of Pharmaceutics, Faculty of Pharmacy and Novel Drug Delivery Systems Research Centre, \\ Isfahan University of Medical Sciences, P.O. Box 81745-359, Isfahan 81746-73461, Iran \\ Correspondence should be addressed to J. Varshosaz; varshosaz@pharm.mui.ac.ir
}

Received 26 July 2013; Revised 18 September 2013; Accepted 23 September 2013

Academic Editor: Patricia Murray

Copyright ( $\odot 2013$ J. Varshosaz et al. This is an open access article distributed under the Creative Commons Attribution License, which permits unrestricted use, distribution, and reproduction in any medium, provided the original work is properly cited.

Background. Drugs with low oral bioavailability due to the first pass metabolism are good candidates for transdermal delivery. Objectives. The aim of this work was preparation of transdermal nanoemulsion of metoprolol which has high first pass metabolism. Methods. Three commercially available types of lecithin (200,100p, and 170), three short chain alcohol (n-butanol, isopropyl alcohol, and n-propanol), and isopropyl myristate (IPM) were used as surfactant, cosurfactant, and oil phase, respectively. The aqueous phase was composed of metoprolol tartrate. Nanoemulsions with different surfactant/cosurfactant weight ratio, various amounts of drug, and different types of alcohol were prepared, and their phase diagrams were studied. Drug release, permeability, and diffusion coefficient of the drug were studied using hairless rat skin. Results. A significant increase in drug solution rate was observed with increasing the metoprolol content in the nanoemulsions, while it decreased when lecithin concentration increased from $40 \%$ to $60 \%$. Increasing the water content resulted in a significant increase in metoprolol release. N-butanol enhanced the drug flux from nanoemulsions more than n-propanol and isopropyl alcohol. The o/w nanoemulsions of metoprolol showed high flux and permeability through the skin. Conclusion. Both w/o and o/w nanoemulsions of metoprolol could enhance permeation and diffusion of metoprolol through rat skin.

\section{Introduction}

The human skin is a readily accessible area for drug delivery. It covers a surface of $2 \mathrm{~m}^{2}$ in an average adult body with the thickness of about $2.97 \pm 0.28 \mathrm{~mm}$ that uptakes one-third of whole blood circulation $[1,2]$. Skin is a barrier that protects the body against chemical and microbial agents; it also controls body temperature and has some roles in controlling blood pressure [2]. Skin consists of three layers: epidermis, dermis, and hypoderm. The epidermis has four regions: basal layer, spiny layer, stratum granulosum, and upper most stratum corneum; the latter consists of keratinized, dehydrated, and highly cornified cells which are inlaid in continuous matrix of lipid membranous sheets constantly replacing internal layers. The water intake of stratum corneum is about $20 \%$. The human skin surface contains average 10-70 hair follicles and 200-250 sweat ducts on every square centimeter area of the skin $[1,3,4]$. Currently, skin is a good candidate for drug delivery and systemic pharmacological approach. Transdermal drug delivery has some benefits: skipping first pass metabolism in liver, steady infusion of a drug over an extended period of time, better compliance of the patient due to ease of usage and reduced frequency of use, a choice for drugs with low therapeutic index and short half life, and so easy elimination of drug when toxicity occurs during the application $[3,5,6]$. Also transdermal drug delivery has some disadvantages such as the possibility of local irritation and skin's low permeability. Considering that variability may occur due to differences in skin permeation due to differences in subcutaneous fat deposition the reduction of inconstancy in the plasma concentration of drug may be restricted. The release of drug from its carrier depends on the concentration of drug in the carrier, physiochemical properties, and presence of polar groups and molecular weight of the drug. Its 
absorbance depends on the application site of use, thickness, temperature, hydration status, and integrity of skin, $\mathrm{pH}$ of the drug, and its molecular size $[1,2,6,7]$.

Nanoemulsions are multiphase systems consisting of water, oil, surfactant, and alcohol, which form a transparent solution. In fact, they are small-scale of emulsions whether oil in water or water in oil with a size range in the order of 5-50 nm, while particle size of dispersed phase in emulsions is $>0.1 \mu \mathrm{m}$, so the emulsions seem milky. The average droplet size in traditional emulsions grows continuously with time, leading to separation of phases due to gravity, but the nanoemulsions are stable, and the particle size does not change during storage [8]. Their ability to solubilize the insoluble drugs and their transparency and constancy make nanoemulsions suitable carriers for transdermal drug delivery $[9,10]$.

The nanoemulsions include four types according to the Winsor's classification: (I) the surfactant is preferentially soluble in water causing the formation of oil-in-water $(\mathrm{o} / \mathrm{w})$ nanoemulsions, (II) the surfactant is remarkably soluble in the oil phase and forms water-in-oil (w/o) nanoemulsions, (III) there is a middle phase having lots of surfactant that coexists with water and oil phases with low amount of surfactant, and (IV) the fourth type is a single-phase micellar solution that forms when a sufficient quantity of amphiphile (an alcohol) is added [11].

Lecithin is a natural surfactant isolated from eggs or soya bean. It can form gels when combined with water and nonpolar solvents. Organogels have gelling agent molecules such as lecithin as a surfactant, a continuous phase of nonpolar solvent, and a polar solvent that is water in most cases $[12,13]$. They have the properties of oil and aqueous based formulations and are clear, viscoelastic, thermodynamically stable, and biocompatible. The organogels have a jelly-like structure with three-dimensional network. A lot of organic solvents such as linear or cyclic alkanes, esters of fatty acids, and amines can be used to form organogels in the presence of lecithin [13]. Lecithin molecules assemble to each other and form enormous cylindrical micelles when a little amount of water, formamide or glycerin is added to the nonpolar media [12]. Lecithin has a wide variety of roles in food industries, pharmaceuticals, and cosmetics as a viscosity modifier, solubilizer, emulsifier, stabilizer, and penetration enhancer [14]. Lecithin consists of phosphatidyl choline, phosphatidyl ethanolamine, phosphatidyl serine, and phosphatidyl inositol and some other substances such as triglycerides and fatty acids [15].

When lecithin is added to the organic media it is dispersed randomly. By adding the trace amount of water the lecithin molecules will assemble in spherical reverse micellar form. Tubular or cylindrical micellar aggregates of lecithin molecules will form when the amount of water is increased. Next step is formation of long, flexible, and worm-like tubular micelle structures in the presence of much more water, and at last these tubular microstructures overlap and entangle with each other to form a three-dimensional gel network among which the organic solvent is entrapped. Some other beneficial properties of organogels are the ability of solving a wide variety of different molecules, resistance to microbial contamination, and optical transparency [12], so they have the essential criteria for transdermal drug delivery.

Microemulsions are homogenous systems by some unique characteristics which make them a good choice for delivering drugs and are widely used in pharmaceutical companies. They have been also used for oral and intramuscular injection routes [16-18]. The lecithin organogels have been used for preparation of local sodium salicylate [16], methimazole [19], and ketoprofen [20].

Intravenous nanoemulsions have been on the market for parenteral nutrition since the 1950s; meanwhile, they have also been used successfully for IV drug delivery [21].

Nanoemulsions were tested on surfaces by the US Army in December 1999 for a broad-spectrum decontamination of anthrax spore surrogates. It was tested again in March 2001 as a chemical decontamination agent. All tests were successful. The technology has been tested on gangrene and Clostridium botulism spores and can even be used on contaminated wounds to salvage limbs. The nanoemulsion technology can be formulated into a cream, foam, liquid, or spray to decontaminate a variety of materials marketed as NANOSTAT (NanoBio Corp.) [22].

Nanoemulsions are being used to deliver either recombinant proteins or inactivated organisms to a mucosal surface to produce an immune response. The first applications, an influenza vaccine and an HIV vaccine, can proceed to clinical trials. Additional research is ongoing to complete the proof of concept in animal trials for other vaccines including hepatitis $\mathrm{B}$ and anthrax. The University of Michigan has exclusively licensed this technology to NanoBio [22].

Metoprolol is a potent $\beta_{1}$-selective adrenergic blocking agent. The $\beta_{1}$-adrenoceptor antagonists are extensively used in various cardiovascular disorders. The oldest drug of this family is propranolol, but because of its blocking effect on smooth and skeletal muscles it is contraindicated in patients with asthma and should be used with caution in diabetic individuals [23]. Now metoprolol is widely used as a first choice drug in the treatment of mild to moderate hypertension and stable angina and is helpful in postinfarction patients [24]. These benefits are gained due to blocking peripheral adrenoceptors, decreasing rennin secretion from kidneys, and decreasing oxygen use in myocard [25].

Unfortunately, this drug undergoes a wide first pass metabolism but this deactivation can be overcome by fabricating the drug in transdermal therapeutic systems [26]. Nair et al. [27] used the combination of iontophoresis with sodium lauryl sulfate and showed augmented metoprolol delivery which rendered skin drug depot eventually released over a period of time. The transdermal matrix films of metoprolol tartrate were also prepared by casting on mercury substrate employing different ratios of polymers, ethyl cellulose (EC) and polyvinyl pyrrolidone (PVP), using dibutyl phthalate (DBT) as a plasticizer [28]. Based on the physical evaluation, in vitro drug release, and permeation characteristics, it was concluded that, for potential therapeutic use, monolithic drug matrix films composed of EC:PVP, may be suitable for the development of a transdermal drug delivery system of metoprolol [28]. Matrix and membrane controlled transdermal therapeutic systems were prepared from methacrylic 
TABLE 1: Formulation of the different types of metoprolol nanoemulsions.

\begin{tabular}{|c|c|c|c|c|c|c|c|c|}
\hline Formulation & $\begin{array}{c}\text { Metoprolol } \\
\text { tartrate }(\mathrm{mg})\end{array}$ & $\begin{array}{c}\text { Lecithin } \\
170(\mathrm{~g})\end{array}$ & $\begin{array}{c}\text { Lecithin } \\
200(\mathrm{~g})\end{array}$ & $\begin{array}{l}\text { Lecithin } \\
\text { 100p (g) }\end{array}$ & $\begin{array}{c}\text { Isopropyl } \\
\text { myristate (g) }\end{array}$ & Butanol (mL) & $\begin{array}{c}\text { Isopropyl } \\
\text { alcohol (mL) }\end{array}$ & n-Propanol (mL) \\
\hline$\overline{F_{1}}$ & 40 & 0.64 & - & - & 0.96 & - & 0.3 & - \\
\hline $\mathrm{F}_{2}$ & 80 & 0.48 & - & - & 0.72 & - & 1.1 & - \\
\hline $\mathrm{F}_{3}$ & 100 & 0.4 & - & - & 0.6 & - & 1.4 & - \\
\hline $\mathrm{F}_{4}$ & 10 & 0.64 & - & - & 0.96 & - & - & 0.4 \\
\hline $\mathrm{F}_{5}$ & 20 & 0.64 & - & - & 0.96 & - & - & 0.2 \\
\hline $\mathrm{F}_{6}$ & 40 & 0.64 & - & - & 0.96 & - & - & 0.6 \\
\hline $\mathrm{F}_{7}$ & 60 & 0.64 & & - & 0.96 & - & - & 0.2 \\
\hline $\mathrm{F}_{8}$ & 40 & - & 0.64 & - & 0.96 & - & - & 0.3 \\
\hline $\mathrm{F}_{9}$ & 40 & - & & 0.64 & 0.96 & - & - & 0.8 \\
\hline $\mathrm{F}_{10}$ & 131 & - & 0.51 & - & 0.17 & - & - & 0.65 \\
\hline $\mathrm{F}_{11}$ & 40 & - & - & - & - & - & - & - \\
\hline $\mathrm{F}_{12}$ & 80 & 0.64 & - & - & 0.96 & - & 0.4 & - \\
\hline $\mathrm{F}_{13}$ & 80 & 0.4 & - & - & 0.6 & - & 0.4 & - \\
\hline $\mathrm{F}_{14}$ & 40 & - & 0.51 & - & 0.17 & - & - & 0.4 \\
\hline $\mathrm{F}_{15}$ & 40 & 0.48 & - & - & 1.12 & - & - & 0.6 \\
\hline $\mathrm{F}_{16}$ & 40 & 0.8 & - & - & 0.8 & - & - & 0.1 \\
\hline $\mathrm{F}_{17}$ & 40 & 0.64 & - & - & 0.96 & 0.7 & - & - \\
\hline
\end{tabular}

polymers (Eudragit NE) applying different sucrose fatty acid esters to control the drug release and cutaneous absorption of metoprolol [29]. Eudragit RL-100 and polyvinyl acetate have also been used in production of the matrix type transdermal drug delivery systems of metoprolol by film casting technique which showed statistically significant reduction in mean blood pressure in methyl prednisolone-induced hypertensive rats [30]. Ghosh et al. [23] studied the effect of n- decyl methyl sulfoxide (nonionic surfactant) as a percutaneous absorption enhancer in permeation rate of metoprolol across human cadaver skin. They used $1.5 \mathrm{~mm}$ polyacrylate patches $(10 \%$ $\mathrm{w} / \mathrm{w}$ ) containing varying concentrations of $\mathrm{n}$-decyl methyl sulfoxide and tested for skin permeation potential. It was found that incorporation of $\mathrm{n}$-decyl methyl sulfoxide up to $3 \% \mathrm{w} / \mathrm{w}$ concentration did not produce any significant change in skin permeation rate. A concentration of $5 \% \mathrm{w} / \mathrm{w}$ of this surfactant showed $40 \%$ enhancement in metoprolol permeation rate. They concluded that metoprolol permeated quite efficiently through both hairless mouse and human cadaver skin when applied from the polyacrylate patch with no significant lag time. Use of electrical outflow has also been reported for increasing drug permeation due to opening skin pores [30].

Considering the different reports on transdermal delivery of metoprolol and the good results obtained by other drugs used in the basis of nanoemulsions for enhanced permeation in the skin, the aim of the present work was to prepare lecithin nanoemulsion for transdermal delivery of metoprolol in the treatment of hypertension. To our knowledge there is no report on the production of metoprolol lecithin based nanoemulsions and, its designing is novel.

\section{Material and Methods}

2.1. Materials. Lecithin 200, 100p were from Locus Meyer industry, Germany, lecithin 170 was from Degussa, Germany, n-butanol, isopropyl alcohol, n-propanol, potassium monohydrogen phosphate $\left(\mathrm{K}_{2} \mathrm{HPO}_{4}\right), \mathrm{NaOH}$, and sodium lauryl sulphate (SLS) were from Merck Chemical Company, Germany, cellulose membrane from Biocin industry, Belgium, isopropyl myristate from Aldrich company, Germany, and metoprolol was from Alborz Darou, Iran, as a gift sample. All the materials were of analytical grades.

2.2. Animals. Healthy male Wistar albino rats weighing 180-280 g were purchased from Pastur Institue, Tehran, Iran. Animals had free access to standard rat chow and tap water ad libitum. They were kept in a temperature-controlled environment in animal house of Isfahan University of Medical Science at $23 \pm 2^{\circ} \mathrm{C}$ with an alternating cycle of $12 \mathrm{~h}$ light and dark.

2.3. Preparation of Lecithin Organogels of Metoprolol. For preparation of lecithin organogels of metoprolol lecithin was added to $40^{\circ} \mathrm{C}$ water while being stirred on a magnetic stirrer at $300 \mathrm{rpm}$. After complete dissolution of lecithin isopropyl myristate was added at room temperature leading to the formation of a turbid lotion. Finally, by adding one of the three short chain alcohols of n-butanol, isopropyl alcohol, or n-propanol as cosurfactants, the organogel was achieved. After the preliminary tests 16 formulations were selected according to the ratio of lecithin/isopropyl myristate and metoprolol percent that are shown in Table 1. Among these formulations one that had the least amount of alcohol was selected as the optimum formulae.

2.4. Lecithin-Oil-Water Phase Diagram. Different amounts of water were added to the lotion of lecithin/isopropyl myristate in fixed ratio of $1: 1.5$. The studied variables were the percent of metoprolol in solution, the type of alcohol (n-propanol, isopropyl alcohol, and n-butanol), and the different amounts of lecithin. Finally, the effect of lecithin amount, metoprolol percent, alcohol type, and the ratio of lecithin/isopropyl 
myristate on the transparent region of nanoemulsion was estimated. As the amount of water increases, the microemulsion turned to a viscous gel. Phase diagrams for the organogel system also demonstrate the behavior of organogel system such as cloudiness, isotropicity, optical transparency, and viscosity.

\subsection{The Nanoemulsion Characteristic of Metoprolol Organogels}

2.5.1. Particle Size Measurements. The mean particle size of nanoemulsions was measured by photon correlation spectroscopy (PCS) at a fixed angle of $90^{\circ}$ (Zetasizer, ZEN 3600, Malvern Instrumental, UK). Nanodispersion was suitably diluted to measure mean particle size and polydispersity index. Dynamic light scattering (also known as photon correlation spectroscopy or quasielastic light scattering) is a technique in physics that can be used to determine the size distribution profile of small particles in suspension or polymers in solution. It can also be used to probe the behavior of complex fluids such as concentrated polymer solutions. So, none of the ingredients of the formulation interfered with the particle size measurements.

2.5.2. Turbidity of Nanoemulsions. All the samples were tested with spectrophotometer at the wave length of $580 \mathrm{~nm}$, and the absorbance was read. Then the absorbance was changed to transmittance.

2.5.3. Birefringency. The microemulsions were assessed through the polarizing microscope. The rotation of scaled sheet shows the birefringency of the system.

2.5.4. Rheologic Characteristics. For investigation of rheologic behavior of the samples a Rheomat device (RM/180 model, Mettler, Germany) was used. The measuring tube diameter was $15.18 \mathrm{~mm}$, the measuring bob diameter was $14 \mathrm{~mm}$, the shear rate was in the range of $6.5-129\left(\mathrm{~S}^{-1}\right)$, and the fill volume was $9 \mathrm{~mL}$. For drawing the rheogram, shear rate was increased for the samples till maximum. The shearing stress was plotted against shear rate.

2.5.5. Drug Release Studies In Vitro. In vitro permeation studies were performed using Franz diffusion cell. The cellulose membrane was previously soaked for $24 \mathrm{~h}$ in PBS in order to open the pores. These membranes were mounted between the donor and receptor compartment of the diffusion cell. $2 \mathrm{~g}$ of the formulated nanoemulsions was placed over the membranes. The receptor compartment of the diffusion cell was filled with phosphate buffer $\mathrm{pH}$ 7.4. The solution in the receptor compartment was constantly and continuously stirred using magnetic stirrer at $37 \pm 2^{\circ} \mathrm{C} .2 \mathrm{~mL}$ samples were withdrawn at predetermined time intervals of $30,60,120,180$, 240 , and $300 \mathrm{~min}$ and replaced with an equal volume of fresh phosphate buffer with the same temperature. The samples were suitably diluted and analyzed to determine drug content using UV spectrophotometer at a wave length of $275.9 \mathrm{~nm}$. All tests were done in triplicate. For each sample there was a blank. The actual concentration of samples was calculated by using

$$
C_{n}=\mathrm{C}+\frac{C_{n-1} \times V}{V_{t}},
$$

where $C_{n}$ is the actual concentration of sample $n, C$ is the apparent concentration, $C_{n-1}$ is the actual concentration of sample $n-1, V$ is the volume of sample, and $V_{t}$ is the volume of total sample.

2.5.6. Measurement of Drug Penetration from Rat Skin. All test conditions in this experiment were as mentioned earlier in previous section but with some modifications; the freshly excised full thickness hairless abdomen skin of male Wistar rat was mounted on glass diffusion cells with the stratum corneum side in intimate contact with donor phase and the dermal side facing the receptor solution. Samples from the receptor compartment were withdrawn at predetermined time intervals, and the concentration of drug released was measured.

2.5.7. The Diffusion Coefficient and Permeation Coefficient Measurements. Flux of drug was estimated from Fick's first law of diffusion:

$$
J_{S}=\frac{1}{S} \frac{d Q}{d t}
$$

in which $S$ is the surface area of diffusion cell and $d Q / d t$ is the slope of drug release curve [5]. For determination of diffusion coefficient the following equation was used:

$$
K=2 C_{\mathrm{o}} \times S\left(\frac{D}{\pi}\right)^{1 / 2}
$$

where $K$ is the slope of the cumulative drug release profile, $C_{\mathrm{o}}$ is the amount of primary drug, $S$ is the surface area of diffusion cell, and $D$ is drug diffusion.

For calculating the permeation of drug, the following was used:

$$
M=P S C_{d} t
$$

where $M$ is the amount of drug released, $P$ is the permeation coefficient, $S$ is the surface area through which drug permeates, and $C_{d}$ is the amount of drug in donor phase [5].

2.6. Data Analysis. For the evaluation of drug release kinetics Excel 2007 software was used, and the statistical analysis was done using SPSS software version 10. All data were expressed as mean \pm SD and were compared by analysis of variance (ANOVA) test followed by the post hoc test of LSD. A significant level of $P<0.05$ was considered in all cases.

\section{Results and Discussion}

3.1. Metoprolol in a Lecithin Base Organogel for Transdermal Delivery in Hypertension. Transdermal drug delivery has its advantages in drug delivery such as elimination of first pass 


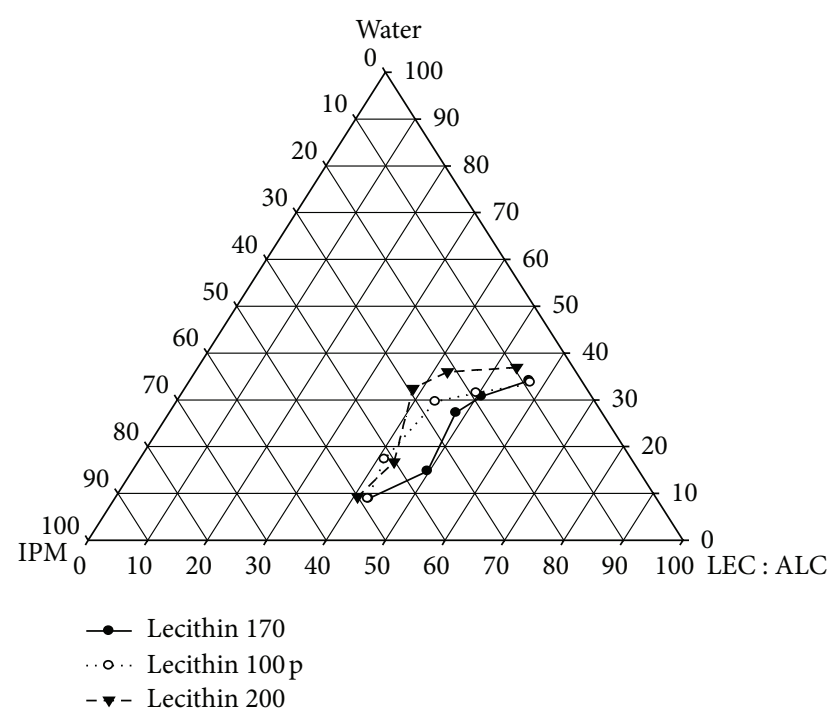

FIGURE 1: The effect of lecithin type on the transparent region of w/o metoprolol nanoemulsion containing IPM/lecithin/isopropyl alcohol/and $0.4 \mathrm{~g}$ of $10 \%$ metoprolol solution (LEC : ALC represents the mixture of lecithin and alcohol used as the surfactant and cosurfactant).

metabolism, ease of application and reduction of inconstancy in the plasma concentration of drug. Metoprolol is an antihypertensive drug with short half life which needs to be used, frequently; meanwhile it goes under a high first pass metabolism so that its oral bioavailability is just $50 \%$. Bioavailability is reduced by about $20-30 \%$ for the controlled release preparation compared to the conventional tablets. Therefore, this drug is a good candidate for transdermal delivery [27-29].

3.2. Formulation Types. In order to increase the permeation of metoprolol, different ratio of soya lecithin and isopropyl myristate (from $90: 10$ to $10: 90$ ) was used. The best ratios of lecithin/IPM were $40: 60,50: 50$, and $30: 70$. The formulations containing more than $50 \%$ of lecithin and less than $30 \%$ could not be prepared, since more than $50 \%$ of lecithin could not be dissolved in IPM, and when its concentration was less than $30 \%$ too much alcohol was needed to prepare the nanoemulsion [31].

3.3. Phase Diagram. Phase diagrams seen in Figures $1-4$ show the effect of lecithin type, alcohol type, drug content, and lecithin/isopropyl myristate ratio on the transparent region of nanoemulsions, respectively.

By increasing purity of lecithin (type 200 was the most pure one and type $100 \mathrm{p}$ had the lowest purity) the transparent region increased (Figure 1) as Nasser and coworkers [32] also showed in their study. By increasing alcohol chain (Figure 2) the transparent region decreased. Trotta et al. [33] reported such a phenomenon in their study too. Increasing drug content (Figure 3) did not change the transparent region, but $15 \%$ of metoprolol decreased the transparent region because of decreasing the surface tension [33]. Changing

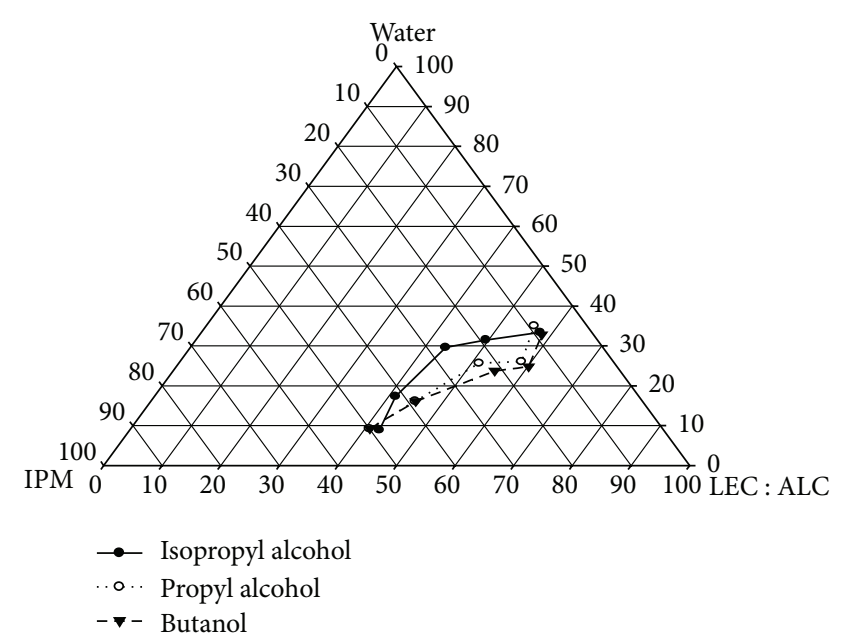

FIGURE 2: The effect of alcohol type on the transparent region of w/o metoprolol nanoemulsion containing IPM/lecithin 170/isopropyl alcohol/and $0.4 \mathrm{~g}$ of $10 \%$ metoprolol solution (LEC : ALC represents the mixture of lecithin and alcohol used as the surfactant and cosurfactant).

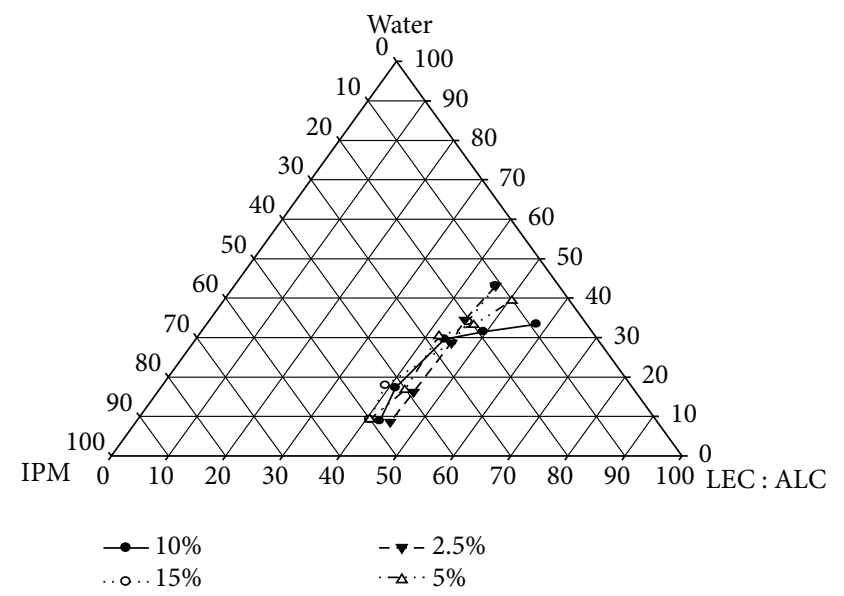

FIGURE 3: The effect of drug content in aqueous solution on the transparent region of w/o metoprolol nanoemulsion containing IPM/lecithin 170/isopropyl alcohol/and aqueous solution of different drug contents (LEC: ALC represents the mixture of lecithin and alcohol used as the surfactant and cosurfactant).

in IPM/lecithin ratio did not change the transparent region (Figure 4).

\subsection{Characteristics of the Nanoemulsions of Metoprolol Organogel}

3.4.1. Turbidity and Particle Size of Nanoemulsions. There is a close and direct relationship between transparency and the particle size. All samples were transparent when seen with eyes and showed a particle size between 17 and $49 \mathrm{~nm}$ except $\mathrm{F}_{3}$ and $\mathrm{F}_{15}$ which had larger particle size. Table 2 shows the transmittance and particle size of the samples. The samples with more transparency and smaller particle size 


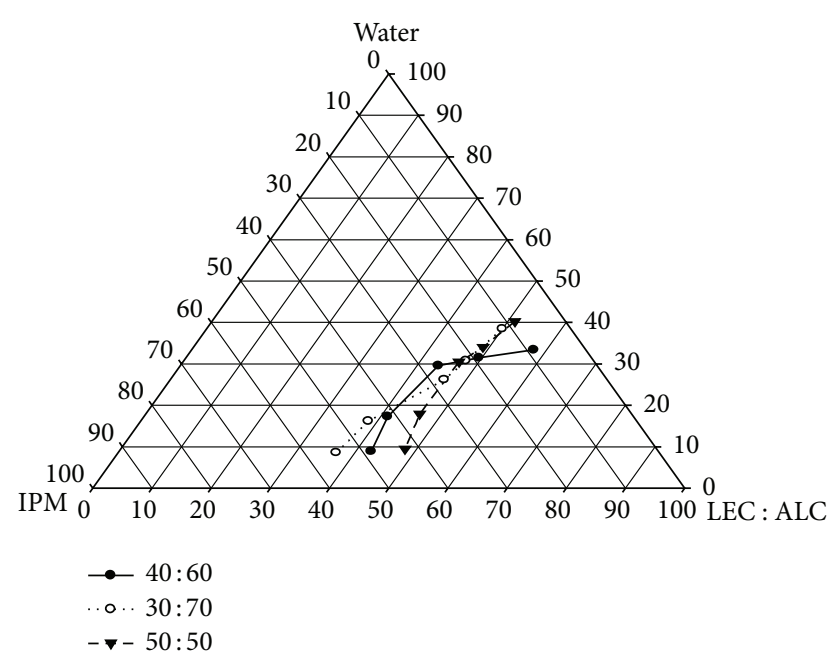

FIGURE 4: The effect of lecithin/IPM ratio on the transparent region of w/o metoprolol nanoemulsion containing IPM/lecithin 170/isopropyl alcohol/and $0.4 \mathrm{~g}$ of $10 \%$ metoprolol solution (LEC: ALC represents the mixture of lecithin and alcohol used as the surfactant and cosurfactant).

TABLE 2: The results of turbidity measurement of nanoemulsions according to the transmittance of light.

\begin{tabular}{lcc}
\hline Formulation & Particle size $(\mathrm{nm})$ & Transmittance $(\%)$ \\
\hline $\mathrm{F}_{1}$ & 34 & 60 \\
$\mathrm{~F}_{2}$ & 20 & 71 \\
$\mathrm{~F}_{3}$ & 256 & 40 \\
$\mathrm{~F}_{4}$ & 44 & 50 \\
$\mathrm{~F}_{5}$ & 42 & 53 \\
$\mathrm{~F}_{6}$ & 40 & 53 \\
$\mathrm{~F}_{7}$ & 49 & 50 \\
$\mathrm{~F}_{8}$ & 17 & 85 \\
$\mathrm{~F}_{9}$ & 47 & 52 \\
$\mathrm{~F}_{10}$ & 19 & 75 \\
$\mathrm{~F}_{11}$ & - & 90 \\
$\mathrm{~F}_{12}$ & 18 & 73 \\
$\mathrm{~F}_{13}$ & 37 & 60 \\
$\mathrm{~F}_{15}$ & 301 & 32 \\
$\mathrm{~F}_{16}$ & 32 & 65 \\
$\mathrm{~F}_{17}$ & 41 & 57 \\
\hline
\end{tabular}

were better choices for studying the drug release parameters. The most transparent formulation was the aqueous solution of metoprolol $\left(\mathrm{F}_{11}\right)$ after that the nanoemulsion of $\mathrm{F}_{8}$ had the highest transparency while $\mathrm{F}_{15}$ was the most turbid one. Both these formulations have similar amounts of drug and are prepared using n-propanol as the cosurfactant, but $\mathrm{F}_{8}$ contains more lecithin 200 which has higher purity than the type of lecithin 170 used in less amounts in $\mathrm{F}_{11}$. The former has also lower amounts of IPM.

DLS method may be used even for suspensions which are dispersed systems with micrometric particles and quite turbid so turbidity of some samples does not interfere with

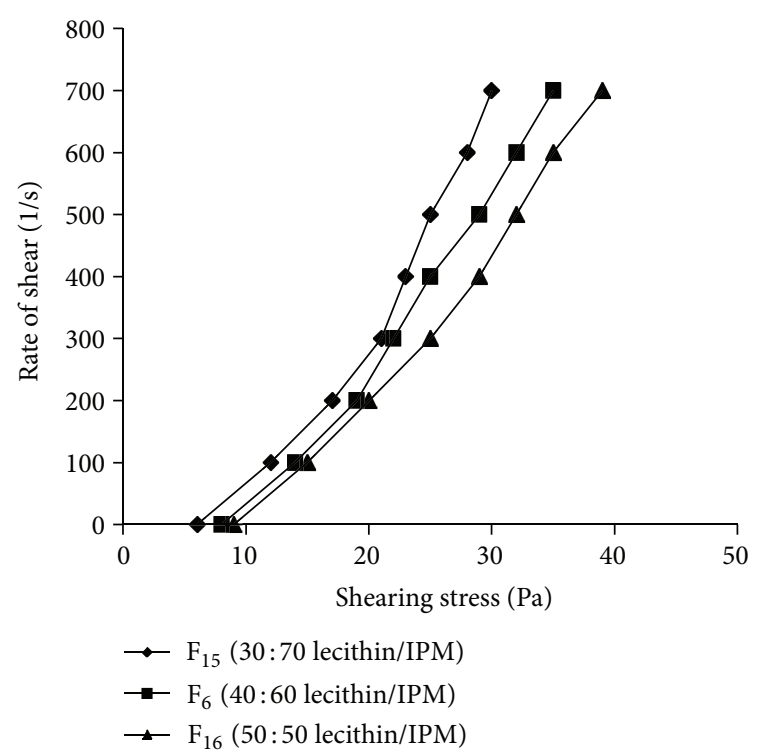

FIGURE 5: The rheogram of w/o metoprolol nanoemulsion containing IPM/lecithin/isopropyl alcohol/and $0.4 \mathrm{~g}$ of $10 \%$ metoprolol solution with different ratios of lecithin 170 : IPM.

the PCS measurements. Moreover, as mentioned in the methods all samples were diluted suitably before particle size measurements.

3.4.2. Birefringency. The microemulsions were assessed through the polarizing microscope; none of the samples showed light scattering; the background was dark; and no birefringency was seen, representing the production of nanoemulsions.

3.4.3. Rheologic Behavior. Flow properties of different nanoemulsions are shown in Figures 5-7. Initially, the flow of organogels did not change by changing the shearing stress, but after a while with the increasing in the rate of shear, shearing stress increased linearly too. Adding the amount of lecithin increased shearing stress (Figure 5), while increased amounts of water decreased it (Figure 6). Changing the amount of drug did not change the shearing stress (Figure 7).

Rheologic behavior is a sign of flow and dispersion of a system and also affects the release process [34, 35]. So knowledge of the rheologic behavior of a transdermal drug delivery system is obviously important. Lecithin organogels show Newtonian behavior before they become gels but by adding water they show non-Newtonian behavior [36]. Three types of flow are seen in these systems: plastic, pseudoplastic, and dilatant flow. As seen in Figures 5-7 all studied formulations had plastic flow behavior; when the organogels were sheared at low shear rates, they behaved like a solid and show elasticity. With a subsequent increase in shear rate, the tubular structures are weakened. The gelling molecules break the physical interactions of the tubules until the shear stress is high enough to destroy the organogel structure, so they flow in linear form [12]. Increasing the ratio of lecithin/IPM from $30: 70\left(\mathrm{~F}_{15}\right)$ to $40: 60\left(\mathrm{~F}_{6}\right)$ and $50: 50\left(\mathrm{~F}_{16}\right)$ increased 


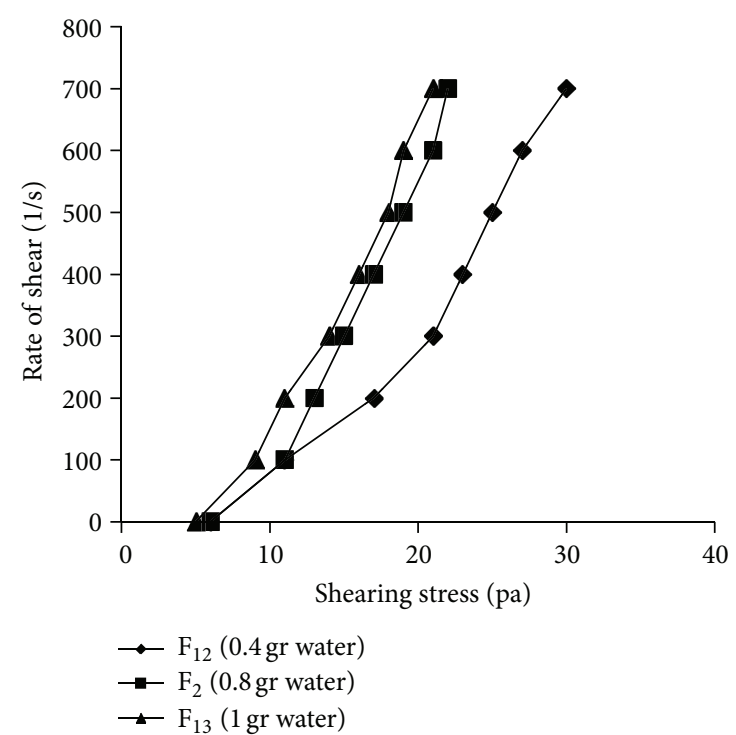

FIGURE 6: The rheogram of w/o metoprolol nanoemulsion containing IPM/lecithin/isopropyl alcohol/and $0.4 \mathrm{~g}$ of $10 \%$ metoprolol solution with different water contents.

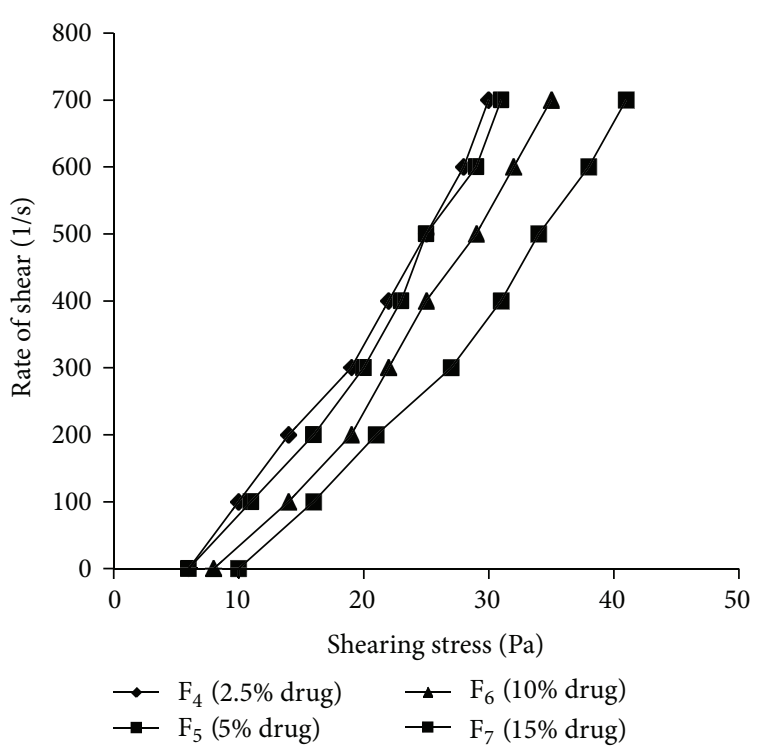

FIGURE 7: The rheogram of w/o metoprolol nanoemulsion containing IPM/lecithin/isopropyl alcohol/and $0.4 \mathrm{~g}$ of different concentrations of metoprolol solution.

viscosity and shearing stress of the formulations (Figure 5). By changing the water content of nanoemulsions from $0.4 \mathrm{~g}$ in $\mathrm{F}_{12}$ to $0.8 \mathrm{~g}$ in $\mathrm{F}_{2}$ and $1 \mathrm{~g}$ in $\mathrm{F}_{13}$ the viscosity and shearing stress decreased too (Figure 6). Nasser and coworkers achieved similar results in their study on the ketorolac thrometamine organogels in which, by increasing the water content of nanoemulsions, the viscosity and shearing stress decreased [31]. Changing the drug content from 2.5 to $15 \%$ did not have significant effect on the rheologic behavior of nanoemulsions, and no change in viscosity was observed (Figure 7).
3.5. In Vitro Drug Release. The results of flux calculation, regression coefficient, and permeation and diffusion of different formulations are written in Table 3.

As Table 3 indicates in formulations of $F_{16}, F_{15}$ and $F_{6}$ the flux and drug release rate is the lowest. In formulation of $\mathrm{F}_{15}$ by increasing the ratio of lecithin: IPM, the coefficients of permeation and diffusion decreased (Table 3). Increasing the lecithin:IPM from 30:70 to 40:60 and 50:50 drug release (flux) decreased; it can be interpreted in this way that thermodynamic activity of drug is decreased in higher concentration of lecithin. In higher concentrations of lecithin there are cylindrical micelles which trap the drug, so the flux of drug and its release rate decreased (Table 3$)(P<0.05)$ (cf. $\mathrm{F}_{16}, \mathrm{~F}_{15}$, and $\mathrm{F}_{6}$ ). Aboofazeli and coworkers achieved similar results in their study on the ketorolac thrometamine organogels [31]. By increasing the drug content from 2.5 to $10 \%$ the rate of drug release enhanced $\left(\mathrm{F}_{4}, \mathrm{~F}_{5}\right.$, and $\left.\mathrm{F}_{6}\right)$, and after that by increasing the drug content to $15 \%$ the rate of release declined again (Table 3$)(P<0.05)$ (compare $\mathrm{F}_{7}$ and $\mathrm{F}_{6}$ ). These results confirm the fact that release profile is attributed to drug concentration. The explanation for this phenomenon is that the thermodynamic activity increases by increasing drug concentration until it reaches the saturated concentration, and after this concentration the thermodynamic activity decreases, and accordingly the release declines. Santoyo and coworkers [37] achieved similar results in their study on piroxicam release from propylene glycol gels. Also Henmi et al. [38] reported that indomethacin release from oily gels consisting of soya phospholipid was directly contributed to the drug concentration.

Increasing water content increased the flux and drug release rate from the formulations (Table 3$)\left(\mathrm{cf} \mathrm{F}_{2}, \mathrm{~F}_{12}\right.$, and $\mathrm{F}_{13}$ ). This is because water can enhance drug permeation from cellulose acetate pores [31]. According to the type of alcohol it was observed that flux was lower in formulations which were prepared by $\mathrm{n}$-propanol and isopropanol than those by n-butanol $(P<0.05)$ (Table 3$)\left(\mathrm{cff}^{\mathrm{F}} \mathrm{F}_{1}, \mathrm{~F}_{17}\right.$, and $\left.\mathrm{F}_{6}\right)$. Npropanol and isopropanol are dispersed majorly in aqueous phase, so drug was trapped in inner phase of w/o emulsions, and consequently its release decreased, but water solubility of n-butanol is lower than the other two alcohols [16]; therefore, it may be concluded that the drug was entrapped more in the outer phase causing the faster and increased flux.

Comparing the drug release rate, flux, permeation, and diffusion from formulations containing $0.4 \mathrm{~g}$ of a $10 \%$ metoprolol solution with nanoemulsions containing the same amount of drug but with a different type of nanoemulsion revealed that $\mathrm{o} / \mathrm{w}$ nanoemulsion formulations released the drug faster than w/o types, because w/o nanoemulsions trap drug more and prevent their fast release; that is, representing drug is passed more in time [10] (compare $\mathrm{F}_{8}$ and $\mathrm{F}_{14}$ ) (Table 3).

Increasing the purity of lecithin decreased the release from formulation where lecithin 100p increased drug permeability more than other lecithin types $(P<0.05)\left(\mathrm{cf.} \mathrm{F}_{9}, \mathrm{~F}_{8}\right.$, and $\mathrm{F}_{6}$ ) (Table 3). This result is contrary to Aboofazeli and coworkers' [16] results that can be interpreted in this way that the more pure lecithin can absorb more water in the core of nanoemulsion and decrease drug release rate as discussed 
TABLE 3: Flux, release rate $(d Q / d t)$, regression coefficient $\left(R^{2}\right)$ of the curve plotted from changes of $d Q$ against $d t$, permeation $(P)$, and diffusion coefficient $(D)$ of different formulations through cellulose acetate membrane and $(\dagger)$ rat skin.

\begin{tabular}{lccccc}
\hline Formulation & Flux $\left(\mu \mathrm{g} / \mathrm{cm}^{2} / \mathrm{min}\right) \pm \mathrm{SD}$ & $d \mathrm{Q} / d t(\mu \mathrm{g} / \mathrm{min}) \pm \mathrm{SD}$ & ${ }^{*} R^{2} \pm \mathrm{SD}$ & $P(\mathrm{~cm} / \mathrm{min}) \pm \mathrm{SD}$ & $D\left(\mathrm{~cm}^{2} / \mathrm{min}\right) \pm \mathrm{SD}$ \\
\hline $\mathrm{F}_{1}$ & $0.29 \pm 0.01$ & $1.53 \pm 0.08$ & $0.971 \pm 0.002$ & $(2.46 \pm 0.28) \times 10^{-4}$ & $(6.60 \pm 0.88) \times 10^{-9}$ \\
$\mathrm{~F}_{2}$ & $9.66 \pm 0.30$ & $51.38 \pm 1.59$ & $0.993 \pm 0.001$ & $(1.63 \pm 0.04) \times 10^{-4}$ & $(2.67 \pm 0.16) \times 10^{-6}$ \\
$\mathrm{~F}_{3}$ & $21.21 \pm 0.21$ & $112.83 \pm 1.12$ & $0.995 \pm 0.005$ & $92.24 \pm 0.02) \times 10^{-4}$ & $(6.38 \pm 0.16) \times 10^{-6}$ \\
$\mathrm{~F}_{6}$ & $1.58 \pm 0.01$ & $6.16 \pm 0.09$ & $0.938 \pm 0.001$ & $(2.76 \pm 0.04) \times 10^{-5}$ & $(2.01 \pm 0.06) \times 10^{-7}$ \\
$\mathrm{~F}_{7}$ & $0.93 \pm 0.03$ & $4.96 \pm 0.19$ & $0.991 \pm 0.002$ & $(1.89 \pm 0.05) \times 10^{-5}$ & $(4.83 \pm 0.39) \times 10^{-8}$ \\
$\mathrm{~F}_{8}$ & $0.70 \pm 0.03$ & $3.73 \pm 0.18$ & $0.964 \pm 0.006$ & $(1.98 \pm 0.09) \times 10^{-5}$ & $(4.31 \pm 0.50) \times 10^{-8}$ \\
$\mathrm{~F}_{9}$ & $1.25 \pm 0.02$ & $6.66 \pm 0.13$ & $0.995 \pm 0.002$ & $(2.92 \pm 0.061) \times 10^{-5}$ & $(2.03 \pm 0.07) \times 10^{-7}$ \\
$\mathrm{~F}_{10}$ & $7.38 \pm 0.26$ & $39.26 \pm 1.39$ & $0.998 \pm 0.001$ & $(4.61 \pm 0.20) \times 10^{-5}$ & $(6.21 \pm 0.52) \times 10^{-7}$ \\
$\mathrm{~F}_{11}$ & $43.00 \pm 1.03$ & $228.68 \pm 5.46$ & $0.964 \pm 0.003$ & $(1.59 \pm 0.03) \times 10^{-3}$ & $(2.65 \pm 0.52) \times 10^{-4}$ \\
$\mathrm{~F}_{12}$ & $4.50 \pm 0.16$ & $24.02 \pm 0.81$ & $0.957 \pm 0.007$ & $(4.64 \pm 0.19) \times 10^{-5}$ & $(5.32 \pm 0.40) \times 10^{-7}$ \\
$\mathrm{~F}_{13}$ & $9.00 \pm 0.13$ & $47.92 \pm 0.70$ & $0.993 \pm 0.001$ & $(1.59 \pm 0.01) \times 10^{-4}$ & $(2.87 \pm 0.07) \times 10^{-6}$ \\
$\mathrm{~F}_{14}$ & $5.32 \pm 0.16$ & $28.30 \pm 0.91$ & $0.993 \pm 0.007$ & $(1.33 \pm 0.11) \times 10^{-6}$ & $(3.43 \pm 0.55) \times 10^{-6}$ \\
$\mathrm{~F}_{15}$ & $5.32 \pm 0.16$ & $28.30 \pm 0.91$ & $0.987 \pm 0.001$ & $(2.96 \pm 0.25) \times 10^{-5}$ & $(2.11 \pm 0.30) \times 10^{-7}$ \\
$\mathrm{~F}_{16}$ & $0.65 \pm 0.02$ & $3.46 \pm 0.12$ & $0.986 \pm 0.001$ & $(1.93 \pm 0.06) \times 10^{-5}$ & $(4.37 \pm 0.36) \times 10^{-8}$ \\
$\mathrm{~F}_{17}$ & $2.62 \pm 0.03$ & $13.96 \pm 0.17$ & $0.993 \pm 0.001$ & $(5.19 \pm 0.08) \times 10^{-5}$ & $(7.11 \pm 0.24) \times 10^{-7}$ \\
$\dagger \mathrm{F}_{2}$ & $3.38 \pm 0.17$ & $18.00 \pm 0.89$ & $0.961 \pm 0.001$ & $(3.68 \pm 0.21) \times 10^{-5}$ & $(8.29 \pm 0.27) \times 10^{-7}$ \\
$\dagger \mathrm{F}_{11}$ & $22.24 \pm 0.21$ & $118.30 \pm 1.21$ & $0.987 \pm 0.001$ & $(4.53 \pm 0.06) \times 10^{-4}$ & $(2.76 \pm 0.05) \times 10^{-5}$ \\
$\dagger \mathrm{F}_{10}$ & $3.07 \pm 0.20$ & $16.37 \pm 1.04$ & $0.960 \pm 0.001$ & $(2.47 \pm 0.15) \times 10^{-5}$ & $(5.32 \pm 0.83) \times 10^{-8}$ \\
\hline & & & &
\end{tabular}

earlier about the effect of water content of nanoemulsions on the drug release rate and flux.

Comparing the drug release rate through the cellulose acetate membrane and rat skin $\left(\uparrow \mathrm{F}_{2}, \dagger \mathrm{F}_{10}\right.$, and $\left.\uparrow \mathrm{F}_{11}\right)$ it was observed that in all formulations the flux and drug release rate was higher when using cellulose acetate membrane $(P<$ 0.05) (Table 3). It is similar to the study of Malaz et al. [39] on release profile of tretinoin gels through synthetic membrane and rat skin. This low release of drug through rat skin relates to complexity of skin texture which does not allow drug molecules to penetrate.

The release rate and flux of metoprolol from an aqueous solution $\left(\mathrm{F}_{11}\right)$ through rat skin was more than both w/o $\left(\mathrm{F}_{2}\right)$ and $\mathrm{o} / \mathrm{w}\left(\mathrm{F}_{10}\right)$ types of nanoemulsions $(P<0.05)$ (Table 3$)$ due to drug entrapment in nanoemulsions. Drug release rate, or flux in rat skin did not differ so much in $\mathrm{w} / \mathrm{o}\left(\dagger \mathrm{F}_{2}\right)$ and $\mathrm{o} / \mathrm{w}$ $\left(\dagger \mathrm{F}_{10}\right)$ nanoemulsions type $(P>0.05)$ (Table 3$)$.

Increase in the amount of flux enhances drug permeation and diffusion coefficient. Drug permeation and diffusion coefficient were more in the formulations studied by cellulose acetate membrane than rat skin (Table 3 ) (cf. $\mathrm{F}_{2}, \mathrm{~F}_{10}$, and $\mathrm{F}_{11}$ with $\dagger F_{2}, \dagger F_{10}$, and $\left.\dagger F_{11}\right)$. The highest flux and permeation was seen in $\mathrm{F}_{11}$ (aqueous drug solution) and the lowest was seen in $\mathrm{F}_{10}(\mathrm{o} / \mathrm{w}$ types of nanoemulsion $)(P<0.05)$.

In spite of promising results obtained from nanoemulsions for transdermal uses attention to toxicological aspects of nanosized delivery systems should not be ignored. Lipid-based nanoparticles such as liposomes, micelles, and nanoemulsions are platforms that must be compatible with the physiological environment and prevent undesirable interactions with the immune system. At present there is little experimental evidence on the potential toxicity of nanoemulsions [40]. Nevertheless, there are a number of physicochemical and physiological mechanisms associated with the small particle size in nanoemulsions that could potentially cause toxicity. Avoiding immune stimulation or suppression is an important consideration when developing new strategies in drug and gene delivery. The organic solvents are usually removed by evaporation during the preparation of the nanoemulsions, but some residual solvent may remain in the final product. It is therefore important to be aware of the potential toxic effects associated with any residual organic solvents if nanoemulsions are produced using this approach. The potential toxicity of emulsifiers and solvents that are suitable for utilization within foods, pharmaceuticals, and other consumer products has been published by various organizations, including the World Health Organization [41]. In the present study all FDA accepted ingredients were used, and no toxicity has been reported for them so far. There are also many reports on the safety of transdermal nanoemulsions. For example, the in vivo toxicity of meloxicam nanoemulsion gel was assessed by histopathological examination in rat which turned out to be nonirritant and biocompatible [42]. Also there was no observed mortality or any signs of toxicity during the experimental period of using thymoquinone-rich fraction nanoemulsions [43].

\section{Conclusion}

$\mathrm{O} / \mathrm{w}$ nanoemulsion released higher amount of metoprolol through cellulose acetate membrane compared to w/o nanoemulsions; however, permeation and diffusion of drug through rat skin from w/o and o/w nanoemulsion did not differ significantly. Formulations containing 10\% aqueous solution of metoprolol had higher drug release rate, and those containing lecithin 200 were preferred because of using less alcohol for elucidating the systems. 


\section{Conflict of Interests}

The authors declare no conflict of interests.

\section{Acknowledgment}

The authors acknowledge the financial support of Isfahan University of Medical Sciences.

\section{References}

[1] E. Keleb, R. K. Sharma, E. B. Mosa, and A. A. Zaljahwi, "Transdermal drug delivery system-design and evaluation," International Journal of Advances in Pharmaceutical Sciences, vol. 1, no. 3, pp. 201-211, 2010.

[2] L. Brunton, B. Chabner, and B. Knollman, Goodman and Gilman's the Pharmacological Basis of Therapeutics, McGrowHill, New York, NY, USA, 12th edition, 2010.

[3] M. Omranifard, M. R. Ardakani, A. Abbasi, and A. S. Moghadam, "Follicular isolation technique with de-epithelialization for eyebrow and eyelash reconstruction," Plastic and Reconstructive Surgery, vol. 130, no. 3, pp. 571-578, 2012.

[4] E. C. Paes, H. J. L. J. M. Teepen, W. A. Koop, and M. Kon, "Perioral wrinkles: histologic differences between men and women," Aesthetic Surgery Journal, vol. 29, no. 6, pp. 467-472, 2009.

[5] R. Aboofazeli, H. Zia, and G. T. Needham, "Transdermal delivery of nicardipine: an approach to in vitro permeation enhancement," Drug Delivery, vol. 9, no. 4, pp. 239-247, 2002.

[6] N. Sharma, B. Parashar, S. Sharma, and U. Mahajan, "Blooming pharma industry with transdermal drug delivery system," Indo Global Journal of Pharmaceutical Sciences, vol. 2, pp. 262-278, 2012.

[7] G. A. van Buskirk, M. A. González, V. P. Shah et al., "Scale-up of adhesive transdermal drug delivery systems," Pharmaceutical Research, vol. 14, no. 7, pp. 848-852, 1997.

[8] R. Y. Parapat, M. Wijaya, M. Schwarze, S. Selve, M. Willinger, and R. Schomäcker, "Particle shape optimization by changing from an isotropic to an anisotropic nanostructure: preparation of highly active and stable supported Pt catalysts in nanoemulsions," Nanoscale, vol. 5, no. 2, pp. 796-805, 2013.

[9] L. Chen, F. Tan, J. Wang, and F. Liu, "Nanoemulsion: a novel transdermal delivery system to facilitate skin penetration of indomethacin," Pharmazie, vol. 67, no. 4, pp. 319-323, 2012.

[10] D. W. Osborne, A. J. I. Ward, and K. J. O’Neill, "Nanoemulsions as topical drug delivery vehicles: characterization of a model system," Drug Development and Industrial Pharmacy, vol. 14, no. 9, pp. 1203-1219, 1988.

[11] P. A. Winsor, "Hydrotropy, solubilisation and related emulsification processes-part I," Transactions of the Faraday Society, vol. 44, pp. 376-398, 1948.

[12] S. Raut, S. S. Bhadoriya, V. Uplanchiwar, V. Mishra, S. K. Jain, and A. Gahane, "Lecithin organogel: a unique micellar system for the delivery of bioactive agents in the treatment of skin aging," Acta Pharmaceutica Sinica B, vol. 2, no. 1, pp. 8-15, 2012.

[13] A. Bhatia, B. Singh, K. Raza, S. Wadhwa, and O. P. Katare, "Tamoxifen-loaded lecithin organogel (LO) for topical application: development, optimization and characterization," International Journal of Pharmaceutics, vol. 444, no. 1-2, pp. 47-59, 2013.

[14] B. F. Szuhaj, Lecithins: Sources, Manufacture and Uses, American Oil Chemist's Society, Champaign, Ill, USA, 1989.
[15] W. Martindale and J. E. E. Reynolds, Martindale, the Complete Drug Reference, Royal Pharmaceutical Society, London, UK, 37th edition, 2011.

[16] R. Aboofazeli, S. A. Mortazavi, and P. Khoshnevis, "In vitro release study of sodium salicylate from lecithin based phospholipid microemulsions," Iranian Journal of Pharmaceutical Research, vol. 2, pp. 95-101, 2003.

[17] W. A. Ritschel, "Microemulsions for improved peptide absorption from the gastrointestinal tract," Methods and Findings in Experimental and Clinical Pharmacology, vol. 13, no. 3, pp. 205220, 1991.

[18] J. M. Sarciaux, L. Acar, and P. A. Sado, "Using microemulsion formulations for oral drug delivery of therapeutic peptides," International Journal of Pharmaceutics, vol. 120, no. 2, pp. 127136, 1995.

[19] S. B. Hoffman, A. R. Yoder, and L. A. Trepanier, "Bioavailability of transdermal methimazole in a pluronic lecithin organogel (PLO) in healthy cats," Journal of Veterinary Pharmacology and Therapeutics, vol. 25, no. 3, pp. 189-193, 2002.

[20] D. Paolino, C. A. Ventura, S. Nisticò, G. Puglisi, and M. Fresta, "Lecithin microemulsions for the topical administration of ketoprofen: percutaneous adsorption through human skin and in vivo human skin tolerability," International Journal of Pharmaceutics, vol. 244, no. 1-2, pp. 21-31, 2002.

[21] C. M. Keck, M. Jansch, and R. H. Müller, "Protein adsorption patterns and analysis on IV nanoemulsions-the key factor determining the organ distribution," Pharmaceutics, vol. 5, no. 1, pp. 36-68, 2013.

[22] P. Shah, D. Bhalodia, and P. Shelat, "Nanoemulsion: a pharmaceutical review," Systematic Reviews in Pharmacy, vol. 1, no. 1, pp. 24-32, 2010.

[23] T. K. Ghosh, M. J. Habib, K. Childs, and M. Alexander, “Transdermal delivery of metoprolol-I: comparison between hairless mouse and human cadaver skin and effect of n-decylmethyl sulfoxide," International Journal of Pharmaceutics, vol. 88, no. 1-3, pp. 391-396, 1992.

[24] H. Fares, C. J. Lavie, and H. O. Ventura, "Vasodilating versus first-generation $\beta$-blockers for cardiovascular protection," Postgraduate Medicine, vol. 124, no. 2, pp. 7-15, 2012.

[25] G. K. McEvoy and E. K. Snow, AHFS Drug Information, American Society of Health System Pharmacists, 54th edition, 2013.

[26] G. S. Anisree, C. Ramasamy, J. I. Wesley, and B. M. Koshy, "Formulation of transdermal drug delivery system of metoprolol tartrate and its evaluation," Journal of Pharmaceutical Sciences and Research, vol. 4, pp. 1939-1942, 2012.

[27] A. Nair, H. Vyas, J. Shah, and A. Kumar, "Effect of permeation enhancers on the iontophoretic transport of metoprolol tartrate and the drug retention in skin," Drug Delivery, vol. 18, no. 1, pp. 19-25, 2011.

[28] D. C. Bhatt, A. S. Dhake, R. K. Khar, and D. N. Mishra, "Development and in vitro evaluation of transdermal matrix films of metoprolol tartrate," Yakugaku Zasshi, vol. 128, no. 9, pp. 1325$1331,2008$.

[29] G. Csóka, S. Marton, R. Zelko, N. Otomo, and I. Antal, "Application of sucrose fatty acid esters in transdermal therapeutic systems," European Journal of Pharmaceutics and Biopharmaceutics, vol. 65, no. 2, pp. 233-237, 2007.

[30] R. Vanbever, N. Lecouturier, and V. Preat, "Transdermal delivery of metoprolol by electroporation," Pharmaceutical Research, vol. 11, no. 11, pp. 1657-1662, 1994. 
[31] A. A. Nasser, R. Aboofazeli, H. Zia, and T. E. Needham, "Lecithin stabilized nanoemulsion based organogels for topical application of ketorolac tromethamine-II: in vitro release study," Iranian Journal of Pharmaceutical Research, vol. 2, pp. 117-124, 2003.

[32] A. A. Nasser, R. Aboofazel, H. Zia, and T. G. Needham, "Lecithin stabilized nanoemulsions: an organogel for topical application of ketorolac tromethamine-I: phase behavior studies," Iranian Journal of Pharmaceutical Research, vol. 2, no. 1, pp. 59-63, 2003.

[33] M. Trotta, F. Pattarino, and G. Grosa, "Formation of lecithinbased microemulsions containing n-alkanol phosphocholines," International Journal of Pharmaceutics, vol. 174, no. 1-2, pp. 253259, 1998.

[34] G. Betageri and P. Sunil, "Semisolid preparation," in Encyclopedia of Pharmaceutical Technology, J. Swarbrick and J. C. Boylan, Eds., pp. 2436-2438, Marcel Dekker, London, UK, 2nd edition, 2002.

[35] J. Wagner, Biopharmaceutics and Relevant Pharmacokinetics, Drug Intelligence Publications, Hamilton, Ill, USA, 1st edition, 1971.

[36] R. Kumar and O. P. Katare, "Lecithin organogels as a potential phospholipid-structured system for topical drug delivery: a review," AAPS PharmSciTech, vol. 6, no. 2, pp. E298-E310, 2005.

[37] S. Santoyo, A. Arellano, P. Ygartua, and C. Martín, "In vitro percutaneous absorption of piroxicam through synthetic membranes and abdominal rat skin," Pharmaceutica Acta Helvetiae, vol. 71, no. 2, pp. 141-146, 1996.

[38] T. Henmi, M. Fujii, K. Kikuchi, N. Yamanobe, and M. Matsumoto, "Application of an oily gel formed by hydrogenated soybean phospholipids as a percutaneous absorption-type ointment base," Chemical and Pharmaceutical Bulletin, vol. 42, no. 3, pp. 651-655, 1994.

[39] M. Malaz, N. Tavakoli, and R. Ebrahimi, "Physicochemical evaluation, stability and release stability studies of tertinoin local products," Medical Journal of Hormozgan University, vol. 8, no. 4, pp. 199-207, 2005.

[40] F. Shakeel, S. Shafiq, N. Haq, F. K. Alanazi, and I. A. Alsarra, "Nanoemulsions as potential vehicles for transdermal and dermal delivery of hydrophobic compounds: an overview," Expert Opinion on Drug Delivery, vol. 9, no. 8, pp. 953-974, 2012.

[41] D. J. McClements and J. Rao, "Food-grade nanoemulsions: formulation, fabrication, properties, performance, biological fate, and potential toxicity," Critical Reviews in Food Science and Nutrition, vol. 51, no. 4, pp. 285-330, 2011.

[42] S. Khurana, N. K. Jain, and P. M. Bedi, "Nanoemulsion based gel for transdermal delivery of meloxicam: physico-chemical, mechanistic investigation," Life Sciences, vol. 92, no. 6-7, pp. 383-392, 2013.

[43] Z. Tubesha, M. U. Imam, R. Mahmud, and M. Ismail, "Study on the potential toxicity of a thymoquinone-rich fraction nanoemulsion in sprague dawley rats," Molecules, vol. 18, no. 7, pp. 7460-7472, 2013. 

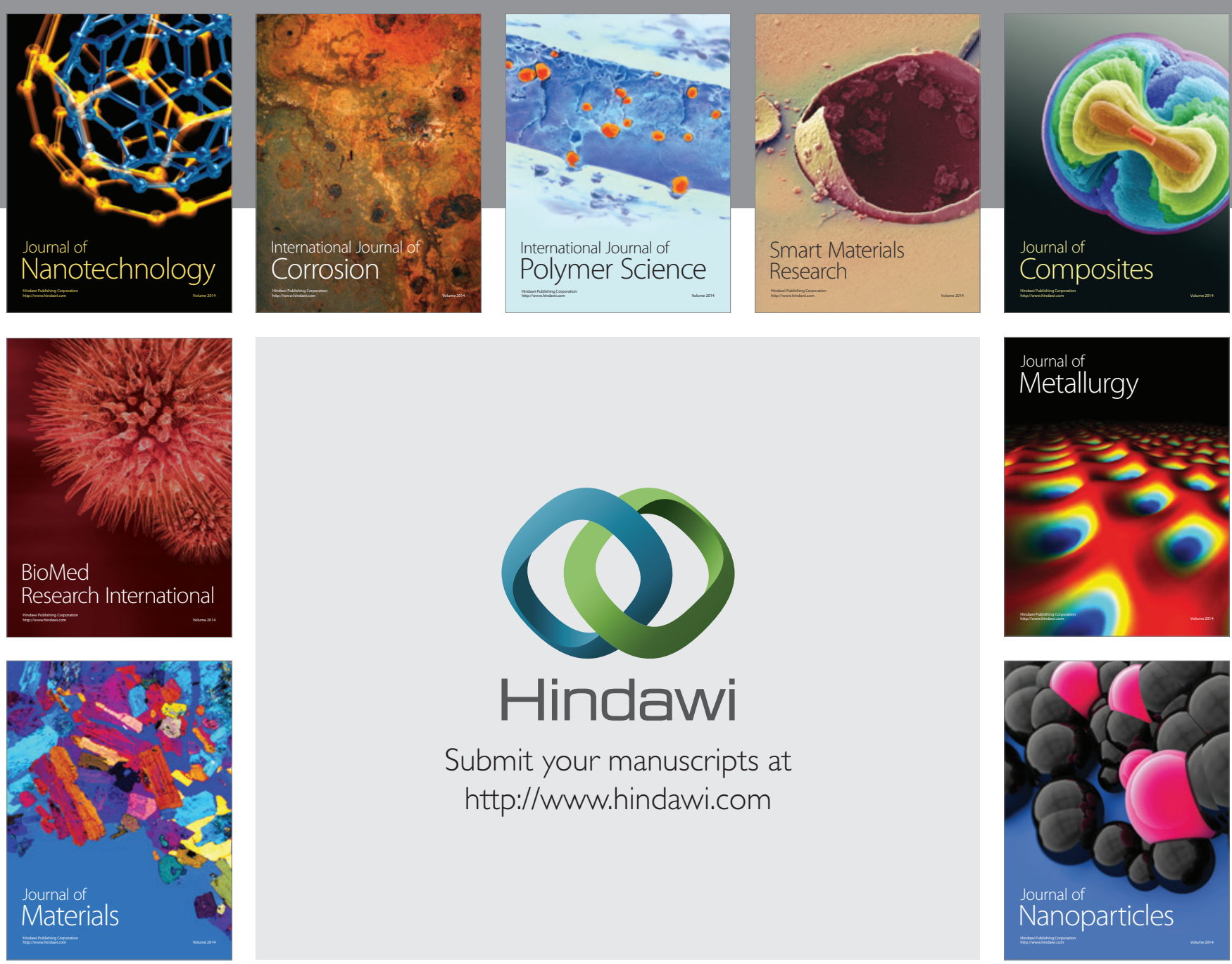

Submit your manuscripts at http://www.hindawi.com
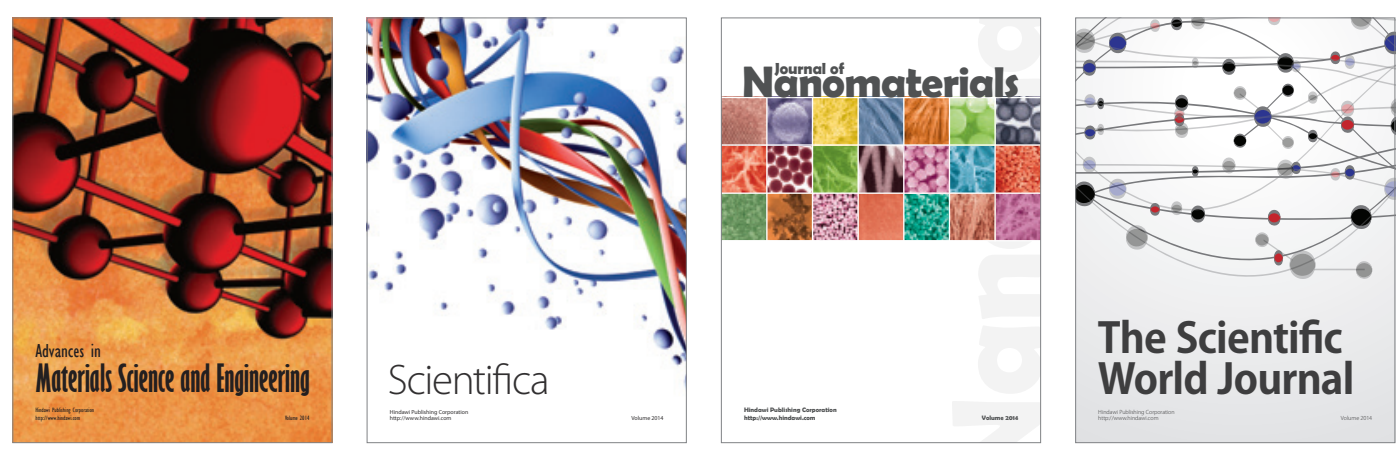

\section{The Scientific World Journal}
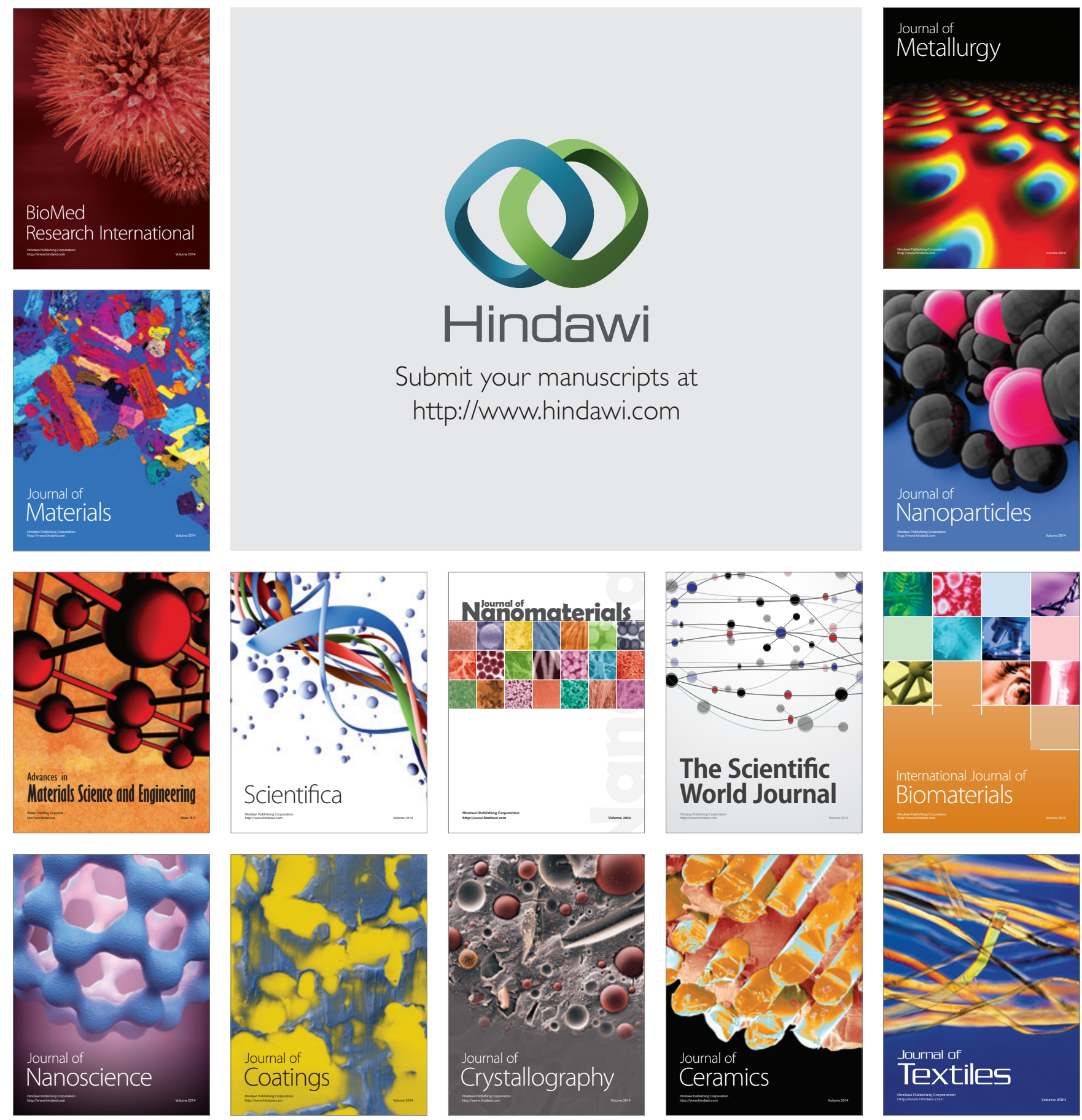